\title{
Characteristics of self referred patients attending minor injury units
}

\author{
Department of \\ General Practice and \\ Primary Care, King's \\ College School of \\ Medicine and \\ Dentistry, London SE5 \\ B Dolan

Accident and
Emergency
Department, King's
College Hospital,
London SE5
J Dale
Correspondence to:
Dr Brian Dolan, Department
of General Practice and
Primary Care, King's College
School of Medicine and
Dentistry, Bessemer Road,
London SE5 9PJ.
Accepted for publication
27 March 1997

\author{
Brian Dolan, Jeremy Dale
}

published research in this area. In particular, little is known about patients' use and understanding of the services provided by MIUs.

In this study we aimed to describe patients attending two MIUs. The study was undertaken as part of a review into minor injuries services in South East Kent. The MIUs studied were situated in Folkestone and Deal. They serve a mix of urban and rural populations which are swelled in the summer months by tourists and foreign language students. Both MIUs previously had 24 hour A\&E provision and were redesignated as MIUs in the late 1970s. In 1993, Folkestone MIU saw 17396 new patients and Deal MIU saw 7801 new patients.

The hours of opening of the MIUs were 9 am to $6 \mathrm{pm}$ at Folkestone and 8 am to $6 \mathrm{pm}$ in Deal, seven days a week. Both MIUs have access to $x$ ray facilities, which were available on weekdays only. At the time of the study, all patients attending the MIUs with new problems were seen by a registered nurse before being treated by a clinical assistant. In Folkestone the clinical assistants worked a rota and were available throughout the hours of opening. In Deal, local general practitioners formed an on call rota and were contacted by nursing staff, who instituted immediate and necessary treatments while awaiting their arrival. None of the nurses acted as emergency nurse practitioners.

\section{Methods}

Over a 10 and an 11 day period in January and February 1994, Folkestone and Deal MIUs saw a total of 586 new patients. A trained interviewer approached patients presenting with new problems while they waited in the waiting room. The aim was to include all the patients seen during the study period. However, $87(14.8 \%)$ were missed because of the unavailability of the interviewer due to rest breaks which were taken at random times during the day to reduce recruitment bias. Of the remaining 499 patients, $27(5.4 \%)$ required immediate treatment, $11(2.2 \%)$ declined to be interviewed, and $149(29.9 \%)$ did not meet the inclusion criteria as they were referrals, reattenders, or follow ups. As a result, 312 self referred patients attending with new problems, or their guardians in the case of children, were interviewed with a structured questionnaire. The questionnaire included reasons for the patient's attendance, their presenting condition, and previous use of health services. 
Table 1 Characteristics of patients $(n=312)$

\begin{tabular}{lc}
\hline Gender & \\
Male & $171(54.8 \%)$ \\
Female & $141(45.2 \%)$ \\
Age range of patients (years) & \\
$<15$ & $78(25 \%)$ \\
$15-25$ & $60(19.2 \%)$ \\
$26-35$ & $34(10.9 \%)$ \\
$36-60$ & $78(25 \%)$ \\
$61-75$ & $30(9.6 \%)$ \\
$>75$ & $12(3.8 \%)$ \\
Where patients came from & \\
Home & $214(68.6 \%)$ \\
Work & $41(13.1 \%)$ \\
Other (eg, public places or homes of & \\
relatives) & $57(18.3 \%)$ \\
Travelling time to MIUs & \\
10 minutes or less & $268(86 \%)$ \\
$11-15$ minutes & $22(7 \%)$ \\
Over 16 minutes & $22(7 \%)$ \\
Means of transport to MIUs (n=312) & \\
Car-self driven & $60(19.2 \%)$ \\
Car-driven by other & $156(50 \%)$ \\
Walking & $58(18.6 \%)$ \\
Taxi & $17(5.4 \%)$ \\
Bus & $8(2.6 \%)$ \\
Other & $13(4.2 \%)$ \\
Duration of illness & \\
6 h or less & $119(38.1 \%)$ \\
$6-24$ h & $115(36.9 \%)$ \\
$>24 \mathrm{~h}$ & $78(25 \%)$ \\
\hline
\end{tabular}

\section{Results}

As shown in table 1, the age of patients was skewed towards the young adult, with 94 (30.1\%) aged 15-35 years. Additionally, 38 patients $(12.1 \%)$ were under 5 years of age, 28 $(8.9 \%)$ were $6-10$, and $32(10.3 \%)$ were 11-15. The majority of patients attended from home using private cars, and presented a problem of less than 24 hours' duration. Journey times to the MIU tended to be very brief, with most being less than 10 minutes' duration.

Two hundred and sixty five patients $(84.9 \%)$ presented with a minor injury, which included $119(36.1 \%)$ who attended with musculoskeletal conditions, including sprains, strains, dislocations, and fractures. Fifty seven patients (18.1\%) presented with lacerations, and 35 $(11.2 \%)$ with trauma related swelling such as bruising. Minor illnesses accounted for 47 of attendances $(15.1 \%)$. This included $36 \mathrm{pa}-$ tients $(11.5 \%)$ who presented with abscesses, skin infections, or rashes.

While most patients $(230 ; 73.7 \%)$ expected an examination at the MIU, just one patient $(0.3 \%)$ expected a referral to further services (table 2). Almost one third of patients anticipated requiring an $x$ ray, and a further one third expected sutures or a dressing (table 2).

When asked why they had not seen their own general practitioner, the commonly given reason was a perception that the MIU was more appropriate for their needs on this occasion (table 2). When asked what they would have done if there were no MIU available, 151 $(48.4 \%)$ stated they would have attended an A\&E department, while 91 (29.4\%) stated they would have attended their general practitioner, and the remainder would have self treated or were unsure.

The patients' reported use of health services over the previous year is shown in table 3 . Their use of general practice appears to have been much more frequent than their use of either MIUs or A\&E departments.
Table 2 Patients'expectations

\begin{tabular}{|c|c|c|c|}
\hline \multicolumn{4}{|l|}{ Expectations } \\
\hline \multicolumn{3}{|c|}{ Hoping for examination } & $230(73.7 \%)$ \\
\hline \multicolumn{3}{|c|}{ Hoping for advice } & $95(30.4 \%)$ \\
\hline \multicolumn{3}{|c|}{ Hoping for treatment } & $162(51.9 \%)$ \\
\hline \multirow{2}{*}{\multicolumn{4}{|c|}{$\begin{array}{l}\text { Hoping for investigation } \\
\text { (nb, some patients stated more than one }\end{array}$}} \\
\hline \multicolumn{3}{|c|}{ expectation) } & \\
\hline \multicolumn{4}{|c|}{ Treatments that patients expected to be required $(n=312)$} \\
\hline \multicolumn{3}{|c|}{ Stitches/dressings } & $92(29.5 \%)$ \\
\hline \multicolumn{2}{|l|}{$X$ ray } & & $94(30.1 \%)$ \\
\hline \multicolumn{2}{|l|}{ Anti-tetnus } & & $14(4.5 \%)$ \\
\hline \multicolumn{2}{|l|}{ Other } & & $13(4.1 \%)$ \\
\hline \multicolumn{2}{|l|}{ Referral } & & $1(0.3 \%)$ \\
\hline \multicolumn{2}{|c|}{ Don't know/not sure } & & $98(31.4 \%)$ \\
\hline \multicolumn{4}{|c|}{ Why GP was not seen } \\
\hline \multicolumn{2}{|c|}{ Felt MIU more appropriate } & & $135(43.3 \%)$ \\
\hline \multicolumn{2}{|c|}{ Surgery shut } & & $66(21.2 \%)$ \\
\hline \multicolumn{2}{|c|}{ Wait to see GP too long } & & $41(13.1 \%)$ \\
\hline \multirow{2}{*}{\multicolumn{2}{|c|}{$\begin{array}{l}\text { Not registered with local GP } \\
\text { Other reason/reason not given }\end{array}$}} & & $9(2.9 \%)$ \\
\hline & & & $61(19.6 \%)$ \\
\hline \multicolumn{4}{|c|}{ Table 3 Patients' use of health services } \\
\hline \multicolumn{4}{|c|}{$\begin{array}{l}\text { Use of health services in previous year } \\
(n=312)\end{array}$} \\
\hline \multirow{3}{*}{$\begin{array}{l} \\
1-2 \text { occasions } \\
3 \text { or more } \\
\text { occasions }\end{array}$} & $M I U$ & $A \mathcal{E}^{\circ} E$ & $G P$ \\
\hline & $79(25.3 \%)$ & $44(14.1 \%)$ & $108(34.6 \%)$ \\
\hline & $21(6.7 \%)$ & $17(5.4 \%)$ & $144(46.1 \%)$ \\
\hline Not used & $212(67.9 \%)$ & $251(80.4 \%)$ & $60(19.2 \%)$ \\
\hline
\end{tabular}

\section{Discussion}

We have previously shown that of 1472 patients who self referred to these MIUs, only 28 $(1.9 \%)$ were referred for further assessment and care to a general hospital, of whom eight $(0.5 \%)$ were subsequently admitted. ${ }^{3}$ Four of the latter admissions were for trauma related problems and required stays of less than 24 hours.

The findings presented here provide further information about who uses MIUs and why. They are locally used services, and the conditions presented appear to be predominantly minor injuries of relatively short duration, with patients having clear expectations of the management required. Most patients had decided to attend the MIU on this occasion because they perceived that urgent attention was required, rather than the full facilities of an A\&E department. The ease of access, promptness of care, and patients' perception of their needs appear to be the key determinants leading to use of the MIU in preference to other services. Most patients did not seem to be using an MIU as a substitute for their general practitioner, but only for specific needs such as when they anticipated the need for an $x$ ray or an intervention that was unavailable in general practice. For many patients, this appeared to reflect their previous experience of contacts with health services.

These findings are in keeping with other published work, ${ }^{45}$ but it should be noted that the study is based in one district, and differences in patient characteristics, expectations, and use of health services may exist elsewhere. Furthermore, the study was undertaken during winter months, and it is likely that the characteristics of patients may differ in the summer when tourists and foreign language students attend the MIUs. It is likely that the demand for MIU services also reflects the mix 
of clinical staff (general practitioners, nurses, and nurse practitioners) available at the MIU, and the accessibility of investigative and therapeutic services at the site. Garnett and Elton found that at an MIU that lacked access to $x$ ray facilities $5 \%$ of patients were referred to $\mathrm{A} \& \mathrm{E}$ and $3 \%$ were referred for $x$ rays. ${ }^{5}$

In relation to the representativeness of the study sample, 27 patients $(5.4 \%)$ could not be interviewed because they required immediate treatment. Most of these patients had sustained lacerations or were in considerable pain. As a result, there may have been a slight underestimate of the proportion of patients who present with such problems.

There is inevitably overlap between the roles played by an A\&E department, an MIU, and a GP surgery. MIUs offer open access to the public, access to $x$ ray and treatment room facilities, and-unlike most GP surgeries-do not operate an appointments system. For some patients appointment systems appear to act as a deterrent to attending their general practitioner. There is some evidence that the structural changes that have occurred since the introduction of the new GP contract in 1990 have eroded the personal patient-doctor relationship in general practice ${ }^{6}$ and may be leading to less accessible care. The emphasis on increasing list size in general practice appears to run counter to patients' preferences, and may be adversely influencing satisfaction. ${ }^{7}$ However, the effect that these changes is having on the demand for A\&E and MIU services is difficult to quantify because there are many confounding variables. For example, although larger group practices may be detrimental to the personal continuous care and flexible access for consultation which patients appear to prefer, they may offer a broader range of services, with greater access to practice nurses and treatment room facilities than smaller practices. ${ }^{8}$

When patients were asked what they would have done if there were no MIU available, 159 (51.6\%) said they would have gone to an A\&E department and the remainder would have gone to their general practitioner or self treated. It appears, therefore, that the availability of an intermediate level of care may result in greater overall workload for the health service, but this must be balanced against the clinical and social costs for patients who might be deterred from seeking health care in the absence of a locally available service. Distance-whether based on actual measurement or travelling time-influences accessibil- ity and is one of the most important determinants affecting choice of health care provider. ${ }^{910}$ Both MIUs were at least 10 miles from the nearest $A \& E$ department, and it is noteworthy that $85.9 \%$ of patients said that it took them less than 10 minutes to reach the MIU. Had these services not been available, in addition to greater use of GP and $A \& E$ services there might also have been greater use of emergency ambulance services for patients without easy access to public or private transport. ${ }^{11}$ It was beyond the scope of the study to examine how many patients with minor injuries were seen in local GP surgeries, community pharmacies, or by occupational health services during the same period. A broader study of minor injury care provision across the community would be required to identify the demand for the provision of such services and the overall impact of variations in local access to minor injury care.

Since this study was undertaken the role of the nurses working in the MIUs has expanded considerably and they have undergone a nurse practitioner training programme. There has been a concomitant reduction in the degree of local general practitioner involvement in service delivery, but this has not led to a reduction in patient attendances.

In conclusion, MIUs appear to fill a useful role in maintaining accessibility to minor injury care for local communities, but their cost and clinical effectiveness needs further study.

This study was funded as part of a larger project commissioned by Kent FHSA. We are grateful to Lynda Tyson and Caroline by Kent FHSA. We are grateful to Lynda Tyson and Caroline Grenfell for their assistance
Deal Minor Injuries Units.

1 NHSME. $A$ study of minor injury services. Leeds: Department of Health, 1993

2 Dale J, Dolan B, Lang H. Healthcare in Folkestone and Deal: new directions for the minor injuries units. London: King's A\&E Primary Care Service and Kent FHSA, 1994.

3 Dale J, Dolan B. Do patient's use minor injury units appropriately? J Public Health 1996;18:152-6.

4 Green J, Dale J. Primary care in accident and emergency and general practice: a comparison. Soc Sci Med 1992;35: 987-95.

5 Garnett SM, Elton PJ A treatment service for minor injuries: maintaining equity of access. J Public Health Med 1991;13:260-6.

6 Keeley D. Personal care or the polyclinic? BMJ 1991;302: 1514-6.

7 Baker R. Characteristics of practices, general practitioners and patients related to levels of patients' satisfaction with and patients related to levels of patients' satis

8 Hannay DR, Usherwood TP, Platts M. Practice organization before and after the new contract: a survey of general tion before and after the new contract: a survey of general

9 McKee CM, Gleadhill D, Watson J. Accident and emergency attendance rates: variation among patients from different general practices. Br J Gen Pract 1990;40:150-3.

10 Magnusson G. The role of proximity in the use of hospital emergency departments. Sociol Health Illness 1980;2:20214

11 Brakenbury PH, Jaya-Ratnam JSW. Accident and emergency services - the contribution of the community hospital. Health Trends 1985;17:31-2. 